Dror, E., Jianye Z., Sacks, R., Seppänen, O. (2019). "Indoor Tracking of Construction Workers Using BLE: Mobile Beacons and Fixed Gatewayes vs. Fixed Beacons and Mobile Gateways." In: Proc. 27th Annual Conference of the International. Group for Lean Construction (IGLC), Pasquire C. and Hamzeh F.R. (ed.), Dublin, Ireland, pp. 831-842. DOI: https://doi.org/10.24928/2019/0154. Available at: <www.iglc.net>.

\title{
INDOOR TRACKING OF CONSTRUCTION WORKERS USING BLE: MOBILE BEACONS AND FIXED GATEWAYS VS. FIXED BEACONS AND MOBILE GATEWAYS
}

\author{
Erez Dror $^{1}$, Jianyu Zhao ${ }^{2}$, Rafael Sacks ${ }^{3}$ and Olli Seppänen ${ }^{4}$
}

\begin{abstract}
Automatic resource location monitoring in construction projects empowers managers to make data driven decisions that improve project workflow. Monitoring data can be processed to measure workflow quality and thus for better understanding of effectiveness and efficiency. We compare two methods for deployment of Bluetooth Low Energy (BLE) beacons for indoor resource monitoring - mobile beacons and fixed gateways (MB) vs. fixed beacons and mobile gateways (FB). BLE beacons can be fixed to walls or carried by workers, and can be fixed to material containers and equipment. Using gateways, such as raspberry pi computers or smartphones, one can easily and automatically monitor resource locations. Several field experiments were conducted, both in the laboratory and in construction sites in Finland, Israel, Peru, Netherlands and China. Technical aspects such as setup, direct cost, feasibility and accuracy were compared for two methods - mobile beacons and fixed gateways vs. fixed beacons and mobile gateways - and the performance of each method in providing the data needed for lean construction workflow assessment was assessed. Both methods are effective in monitoring resource locations but differ in their feasibility of implementation in construction sites and in the utility of the data they provide in terms of identifying value adding activities.
\end{abstract}

\section{KEYWORDS}

Gateways, beacons, Bluetooth Low Energy (BLE), lean construction, waste, situational awareness, indoor positioning

MSc graduate, Faculty of Civil and Enviromental Engineering, Technion - Israel Institute of Technology, Haifa Israel, +972 54717 0019, erezdror@gmail.com

2 Doctoral candidate, Department of Civil Engineering, Aalto University, Espoo Finland, +358 50 3394574, jianyu.zhao@aalto.fi

3 Professor, Faculty of Civil and Enviromental Engineering, Technion - Israel Institute of Technology, Haifa Israel, +972 4829 3190, cvsacks@ technion.ac.il

4 Professor of Practice, Department of Civil Engineering, Aalto University, Espoo Finland, +358 50368 0412, olli.seppanen@aalto.fi 


\section{INTRODUCTION}

The real-time location of labour, material and equipment is important information for site managers and safety managers and enables efficient production planning and work efficiency assessment. However, given the complexity of construction sites and the expense of gathering information, construction managers often make decisions with very limited certainty. Lean construction tools and methods such as the Last Planner System, visual management, Plan-Do-Check-Act, waste identification and workflow assessment are already widespread in construction sites, but their full potential remains unrealized due to limited ability to assess the real status and performance on construction sites. Collecting data manually is time consuming and inefficient (Navon and Sacks 2007) and therefore construction managers are forced to make their decisions based on gut feeling or past experience instead of real-time data (Sacks et al. 2013).

IoT and other technologies enable real-time tracking of labour, material and equipment and might be suitable for the complex environment of construction sites. There are several solutions for indoor resource monitoring, including Bluetooth Low Energy (BLE), radio frequency identification (RFID), Ultra-wideband (UWB), laser scanning, videogrammetry and more. The solution must be easy to deploy, provide efficient and accurate location monitoring and be cost effective. The IoT technology chosen for examination in this paper is BLE beacons. A BLE monitoring system includes four components: BLE beacons, a gateway, a web service and cloud-based storage. The authors examined two methods of deployment of such beacons and gateways - mobile beacons and fixed gateways (MB) vs. fixed beacons and mobile gateways (FB) in the field on construction sites in Finland, Israel, Peru, the Netherlands and China. The research questions we sought to answer were:

- Do the MB or FB methods enable effective and efficient tracking the locations of resources, such as labour, material and equipment?

- What are the advantages and disadvantages of each of the methods?

\section{LITERATURE REVIEW}

Production control has been developed over years within the scope of lean construction (Koskela, 1992). For example, the Last Planner System (Ballard, 2000) and LocationBased Management System (Kenley \& Seppänen 2010), together with their integration (e.g. Seppänen et al., 2010), have led to positive progress in operations management in construction. Their success has been successfully recorded in many case studies around the world (Seppänen et al., 2015). These methods have been tested to improve resource efficiency through onsite waste elimination (Ballard, 2000) and to shorten project durations thanks to production control and forecasting (Seppänen et al, 2014).

In order to coordinate the complex flows of labour, materials, space, equipment and products (Sacks, 2016, Golovina, 2016), the construction industry needs innovative management processes and software that exploit automated information collection and intelligent data processing (Sacks et al. 2010, Nath et al., 2015). Production control methods in construction used to rely heavily on social processes and manual input 
(Pradhananga, 2013), but this resulted in human errors and inaccuracy (Costin et al., 2012), which prevent fulfilment of the prospects of lean construction philosophy (Vieira, 2016). There is a need to develop an intelligent real-time platform where all resources can be tracked and analysed to support labour management (Lin et al., 2013), and automate the data recording process (Costin et al., 2012).

Many technologies have been applied for resource tracking in construction, such as passive RFID (Costin et al., 2012), ZigBee (Liu et al., 2007), BLE (Zhao et al., 2017), (Dror, 2018), magnetic field (Park et al., 2016), and Global Positioning System (GPS) (Alarifi et al., 2016). GPS is a mature technology for tracking, but it is not suitable for indoor positioning (Liu et al., 2007). For indoor positioning, among all the technologies, Bluetooth Low Energy (BLE) has proved to be cost-effective because of its high degree of implementation simplicity with minimal infrastructure and ease of calibration (Park et al, 2016), and sufficiently accurate, thus making it, from the implementation perspective, the preferred technology. However, different solutions applying BLE technology have neither been thoroughly discussed nor compared for application to the scope of production control in lean construction. This paper provides a comparative analysis of two BLE indoor positioning solutions serving the purpose of operations management in construction, outlining the potential use cases suitable for the respective methods.

\section{METHODS}

We examined two different methods for indoor positioning in construction sites using BLE technology. The two methods used the same principles: a combination of BLE beacons and gateways. In general, location monitoring systems using BLE sensors comprise four main components: BLE beacons, gateways, a web application and cloud storage. Each BLE beacon continuously transmits a universally unique identifier (UUID) that is detected by a compatible app or operating system running on the gateway. The gateway in turn transmits the UUID signals and the timestamp to the server via mobile network or Wi-Fi, and the data is stored in cloud-based storage. The minimum requirements for the gateway are that it can detect BLE signals and transmit data to the cloud using either mobile networks or Wi-Fi.

\section{FIXED BEACONS - MOBILE GATEWAYS (FB)}

In this method, the beacons are fixed in place on walls or ceilings in the building under construction, while apps installed on workers' mobile smartphones serve as gateways. The beacons transmit the UUIDs, which are detected by the workers' smartphones, which in turn send packets of UUIDs, timestamps and signal strengths to the data analysis engine in the cloud (Figure 1). Additional fixed beacons in site elevators and site offices can be used to track workers more extensively. 
The method requires one-time installation of the beacons in each location. Figure 2 shows a typical distribution of beacons on a typical floor of a residential building in Israel (beacons are marked in green). The beacons require neither infrastructure nor external power source and are fixed in place manually. In the process of positioning the beacons, the location of each beacon is registered using a designated smartphone app interface, matching each physical location to a specific UUID.

Most smartphones available on the market today can receive Bluetooth signals and are connected to cellular networks and are therefore suitable to serve as gateways (Dror, 2018). In order to use smartphones as gateways, a designated app is needed. In the experimental setup, an Android app was implemented for this purpose.
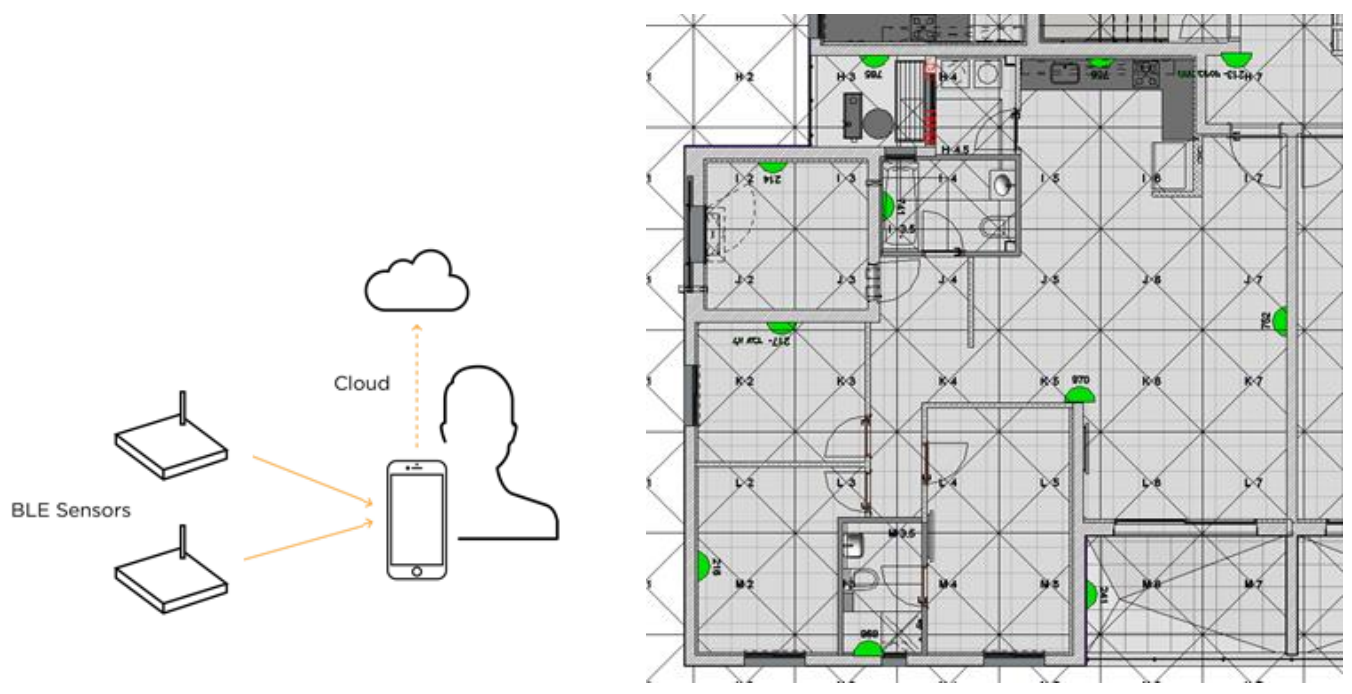

Figure 1 BLE tracking system components

Figure 2 Typical beacon placement in a residential building

\section{MOBILE BEACONS - FIXED GATEWAYS (MB)}

In the MB method, mobile BLE beacons attached to equipment or material containers and carried by workers send signals to gateways that are fixed in place. The proposed prototype contains four main parts (see Figure 3): beacons, gateways, cloud storage and a web-based application. Gateways receive signals from the beacons and transmit them to the cloud service via Wifi or cellular networks (using dongles) (link 4). The cloud software compares the signal strength from beacons and determines the location information based on the strongest signal strength received. The software saves the data in the server and displays the results on a web-based application through an application programming interface (API) (link 5). The application aims to provide situational awareness on site from the perspective of operations management and to update production status based on information from the 
cloud (link 3 and 5). The prototype enables tracking of labor, materials and tools simultaneously (link 1).

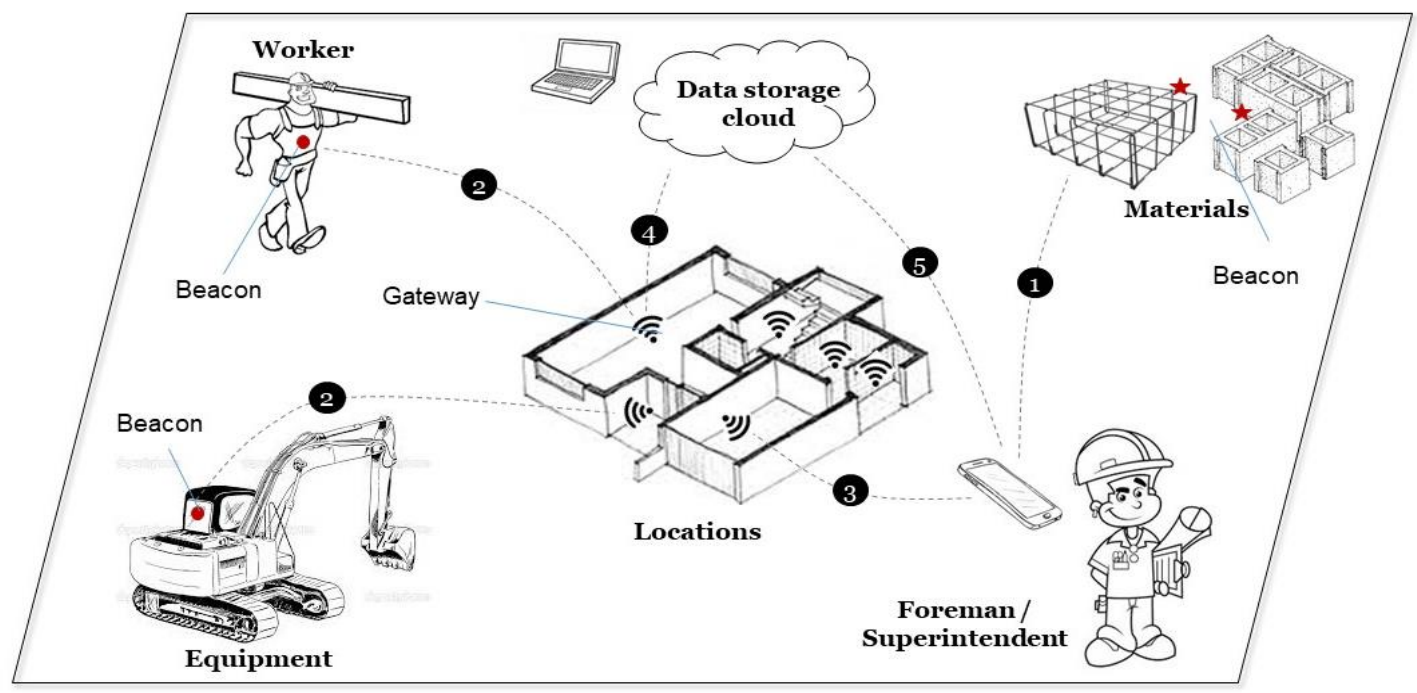

Figure $3 \mathrm{MB}$ indoor positioning solution scheme

\section{COMPARISON}

Each method has its own characteristic advantages and disadvantages. In this section, we compare the two methods in detail from technical, system and lean construction implementation perspectives, considering and proposing possible use cases. Both methods were tested on active construction sites. The MB method was implemented and tested in construction projects in Finland, China, Peru, and the Netherlands, including low rise residential buildings and office buildings. The FB method was implemented and tested in several high-rise residential buildings in Israel.

\section{TECHNICAL AND SYSTEM COMPARISON}

Setup \& maintenance. Both methods require physical setup onsite. The MB solution requires setting up the gateways in their fixed positions. The FB solution requires setting up the beacons in their fixed positions. In both methods the setup process needs around half a day. Additional maintenance work for the system is anticipated to be as much as 12 hours per week.

Cost. When examining the costs, we consider only the hardware costs of the system and not the costs related to developing the software or labour for setup \& maintenance. The costs are split mainly between two components: beacons, gateways.

The MB solution requires a beacon for each item that is to be monitored, gateways, and a power outlet for each of the gateways (in the case studies examined, the gateways were 
positioned in proximity to existing temporary power outlets at no extra cost). The FB solution requires 4-5 beacons for each apartment, no infrastructure, and no gateway purchase - worker's personal smartphones are used as gateways. In both solutions, additional beacons are needed for material and equipment location monitoring. Each element is tagged with a beacon and the number of beacons is the same for both solutions.

As an example, Table 1 details the actual costs for a residential building of three floors with 16 apartments and an entrance floor. The costs assume 15 tracked workers in the building, working with 20 pieces of equipment and up to 30 material containers at a time (beacons are reused).

Table 1: Comparison of example project costs

\begin{tabular}{lll}
\hline & $\begin{array}{c}\text { Fixed beacons - mobile gateways } \\
\text { prototype (FB) }\end{array}$ & $\begin{array}{c}\text { Mobile beacons - fixed } \\
\text { gateways prototype (MB) }\end{array}$ \\
\hline $\begin{array}{l}\text { Hardware } \\
\text { requirements- labor } \\
\text { tracking }\end{array}$ & 65 Beacons & $\begin{array}{l}23 \text { Gateways } \\
15 \text { Beacons }\end{array}$ \\
$\begin{array}{l}\text { Hardware } \\
\text { requirements- } \\
\text { equipment/ material } \\
\text { tracking }\end{array}$ & 50 Beacons & 50 Beacons \\
Total cost & & \\
\hline
\end{tabular}

Feasibility in construction sites. Construction sites are complex environments, with extensive movement of people and vehicles, use of heavy equipment, frequent change of labor and lack of infrastructure such as Wi-Fi signal or electricity. The MB solutions require a stable power supply, which is the biggest obstacle for feasibility testing on site. Therefore, in the tests of MB solutions, the gateways were placed wherever temporary power was available. Data was then analyzed to propose a more rigorous gateway placement strategy for this solution.

The FB solution requires no infrastructure such as Wi-Fi or electricity at all, which makes it highly feasible for construction sites and enables wide spread monitoring. On the other hand, it requires collaboration of the construction workers to allow use of their smartphones. In the case studies, $90 \%$ of workers were carrying a smartphones and were using $3 \mathrm{G}$ network that is widely available in the construction site, however some $20 \%$ of the workers objected, expressing discomfort with the idea of using their personal smartphones to share their locations in the building and on the site.

Coverage \& Accuracy. The coverage and accuracy of the system is related to the ability to position the fixed components: beacons or gateways. The rule of thumb is that the more fixed components placed, the higher the possible location accuracy will be. 
In the prototype $\mathrm{MB}$ method, positioning of the gateway requires access to temporary power. This restricted the positioning to specific locations in the construction site. As the coverage depends on the placement of gateways, location accuracy might be low in buildings with open layout, such as office buildings.

The FB method enables wide spread of beacons in the construction site because it requires no physical infrastructure. It thus enables accurate positioning with unlimited coverage.

Table 2: Technical comparison of the methods

\begin{tabular}{|c|c|c|}
\hline & $\begin{array}{c}\text { Fixed beacons - mobile gateways } \\
\text { prototype (FB) }\end{array}$ & $\begin{array}{l}\text { Mobile beacons - fixed } \\
\text { gateways prototype (MB) }\end{array}$ \\
\hline \multirow[t]{4}{*}{ Setup \& Maintenance } & + Short setup time & + Short setup time \\
\hline & + Minimal maintenance & + Minimal maintenance \\
\hline & $\begin{array}{l}\text { - Application required for the } \\
\text { installation }\end{array}$ & $\begin{array}{l}\text { + Easy set-up, no mobile } \\
\text { application required }\end{array}$ \\
\hline & & $\begin{array}{l}\text { - Gateways are exposed } \\
\text { onsite so they are in risks of } \\
\text { damage or movement }\end{array}$ \\
\hline Cost & + Low hardware costs & - Higher hardware costs \\
\hline \multirow{2}{*}{$\begin{array}{l}\text { Feasibility in } \\
\text { construction sites }\end{array}$} & + Minimum physical requirements & - Requires access to power \\
\hline & - High friction with workers & \\
\hline \multirow[t]{4}{*}{ Accuracy \& Coverage } & + Unlimited coverage & + Coverage and accuracy \\
\hline & + High accuracy in closed areas & $\begin{array}{l}\text { can be improved based on } \\
\text { data analysis heuristics }\end{array}$ \\
\hline & & $\begin{array}{l}\text { - Temporary power } \\
\text { requirements decrease } \\
\text { coverage in most cases }\end{array}$ \\
\hline & & $\begin{array}{l}\text { - Internet is required for } \\
\text { gateways (from onsite WIFI } \\
\text { or mobile network dongles) }\end{array}$ \\
\hline \multirow[t]{2}{*}{ Reliability } & $\begin{array}{l}+98 \% \text { accuracy in apartment scale } \\
\text { positioning }\end{array}$ & $\begin{array}{l}+ \text { Accuracy is high and } \\
\text { detection in real time }\end{array}$ \\
\hline & & $\begin{array}{l}\text { - Signal coverage is not } \\
\text { perfect due to the limitation } \\
\text { from gateway placement }\end{array}$ \\
\hline $\begin{array}{l}\text { Data transmission } \\
\text { rate }\end{array}$ & - Every 5 minutes & + Continuous \\
\hline
\end{tabular}


Data transmission rate. In both methods the BLE beacons transmit their UUID continuously and the data is transferred through the gateway to the cloud storage.

In the MB method, gateways receive signals from the beacons at a frequency of one per second. Because gateways are supplied with power all the time, they can provide a continuous signal scan window, thus making the tracking results very detailed.

In the FB method, because the workers phones serve as gateways, battery drainage aspects must be considered. Therefore, a decision was made to monitor the workers' locations every five minutes, resulting in data gaps of 5 minutes. It is possible to minimize the gap to one minute with little adverse impact on the battery life, but continuous monitoring is not possible.

\section{USE CASE COMPARISON}

Just as different BLE solutions were employed in these two indoor positioning schemes, the requirements and the functionality of each approach can also be different in practical use cases. We have considered three use cases (labor monitoring, material and equipment monitoring, and movement analysis) in Table 3, highlighting the key features of the two approaches.

Table 3. Use case comparison of FB and MB approaches

\begin{tabular}{|c|c|c|}
\hline & $\begin{array}{c}\text { Fixed beacons - mobile gateways } \\
\text { prototype (FB) }\end{array}$ & $\begin{array}{c}\text { Mobile beacons - fixed gateways } \\
\text { prototype (MB) }\end{array}$ \\
\hline \multirow{4}{*}{$\begin{array}{l}\text { Labor } \\
\text { monitoring }\end{array}$} & + High accuracy monitoring & \multirow{2}{*}{$\begin{array}{l}+ \text { Workers need carry only beacons that } \\
\text { have been registered. }\end{array}$} \\
\hline & \multirow{2}{*}{$\begin{array}{l}\text { - Requires smartphone } \\
\text { compatibility and application } \\
\text { installation }\end{array}$} & \\
\hline & & $\begin{array}{l}\text { - Workers might leave beacons on site, } \\
\text { which can cause invalid data }\end{array}$ \\
\hline & $\begin{array}{l}\text { + Workers likely to consistently } \\
\text { carry smartphones }\end{array}$ & $\begin{array}{l}\text { - Limited tracking precision due to lack } \\
\text { of coordinates of floor plan }\end{array}$ \\
\hline $\begin{array}{l}\text { Material \& } \\
\text { Equipment } \\
\text { monitoring }\end{array}$ & \multicolumn{2}{|c|}{$\begin{array}{l}\text { + Beacons can be used as material and equipment tags. Attaching beacons to } \\
\text { material packaging at time of delivery is straightforward, and they can be } \\
\text { reused. }\end{array}$} \\
\hline \multirow{2}{*}{$\begin{array}{l}\text { Movement } \\
\text { data } \\
\text { analysis }\end{array}$} & $\begin{array}{l}+ \text { A movement tendency index can } \\
\text { reflect the workers' efficiency }\end{array}$ & \multirow{2}{*}{$\begin{array}{l}+ \text { Time-location analysis can indicate the } \\
\text { uninterrupted presence level at work } \\
\text { locations for workers }\end{array}$} \\
\hline & $\begin{array}{l}\text { + Gaps in data flow can lead to } \\
\text { gaps in information accuracy }\end{array}$ & \\
\hline
\end{tabular}

\section{CONCLUSION}

The wide-ranging series of experiments has shown that both methods are feasible for resource location monitoring in construction sites. Both provide a robust solution for 
monitoring labor, material and equipment.The FB method has lower cost and greater coverage than the MB method. The degree of resolution of location reporting can be greater with the FB method than for the MB method, since the cost of beacons is significantly lower than that of gateways. The MB method has lower latency of reporting because the fixed gateways can communicate in real-time as they do not have the battery life limitations that apply to smartphones.

Both methods appear to provide sufficiently accurate and complete data for deducing which tasks are underway at any given moment and thus for updating project and process status automatically. The location data itself can be communicated visually to construction managers as an aid to improve their decision making. When it comes to movement data analysis, both methods provide data that can be processed to yield insights about workers' movement patterns and the wastes related to movement and waiting. However, the greater location precision of the FB method is an advantage in this respect, because knowledge of workers' presence or absence from the work face location - often defined as a single room or a single apartment - is necessary to distinguish value adding from non-value adding activity.

\section{LIMITATIONS AND FUTURE RESEARCH}

Both methods share a few implementation limitations. They both require the assent and cooperation of the workers, they both require setup and some maintenance work, and both are subject to vandalism or intentional sabotage. Full scale implementation will require contract terms that ensure cooperation. It is worth mentioning that implementation processes may vary in some countries. The MB method was tested in China, Peru and Finland. Users in China and Peru were more willing to invest resources to ensure the functionality and proper placement of gateways (for example, using power banks instead of temporary power to keep gateways working). They were also more willing to invest in the infrastructure to ensure dense placement of gateways and theft protection. Unlike in China and in Peru, the gateway implementation in Finland was dependent on the availability of power and there was less motivation to invest time or resources. Implementation strategies seem to be dependent on the availability of resources and willingness to invest time and money on new solutions that do not yet have a proven record of positive return on investment.

Future research should focus on examining the features of the two solutions of BLE technologies and apply them in suitable real use cases serving the purpose of production control in construction. Given the success of the experiments with the BLE tracking technology, numerous specific modes of operation can be contemplated. For example: (1) attaching BLE beacons to primary equipment, such as cutting saws, ladders, etc., to provide additional indicators about workers' operations through the day; (2) attaching BLE beacons to palettes of materials to understand actual material flows delivered from warehouse to jobsites; (3) attaching BLE beacons to site managers and providing them a real-time 
interactive monitoring experience for onsite acitivities of workers. All of these can improve the detail and the reliability of the information provided to the work planning process, which can then better improve planning and hence productivity. Futhermore, productivity at work locations could be analyzed in terms of value-adding level and waste spent onsite calculated from the tracking system. In addition, research should also focus on data analysis and visualization of the information to define what information site management teams would like to accuqire to enhance the construction process flow in practice.

\section{ACKNOWLEDGMENTS}

The writers gratefully acknowledge the support of Tidhar Construction Ltd., who collaborated with the bKan research, and the guidance and assistance of Eng. Ronen Barak and Raz Yosef. Addtionally, this work was supported by Tekes (Finnish funding agency for Technology and Innovation) grant number 2819/31/2016

\section{REFERENCES}

Alarifi, A., Al-Salman, A., Alsaleh, M., Alnafessah, A., Al-Hadhrami, S., Al-Ammar, M. A., \& Al-Khalifa, H. S. (2016). Ultra-wideband indoor positioning technologies: Analysis and recent advances. Sensors, 201616(5), 707. doi:10.3390/s16050707

Ballard, G. (2000).The Last Planner System of Control. PhD Thesis, University of Birmingham.

Costin, A., Pradhananga, N. and Teizer, J. (2012) Leveraging Passive RFID Technology for Construction Resource Field Mobility and Status Monitoring in a High-rise Renovation Project. Automation in Construction, 24, 1-15.

Dror, E. (2018). "Improving information flow in construction projects using real-time monitoring and information visualization", MSc Thesis, Technion IIT.

Golovina O., Teizer J., and Pradhananga N. (2016). Heat Map Generation for Predictive Safety Planning: Preventing Struck-by and Near Miss Interactions between Workerson- foot and Construction Equipment. Automation in Construction, 71, pp. 99-115.

Koskela, L. (1992). Application of the new production philosophy to construction (Vol. 72). Stanford: Stanford University.

Lin, P., Li, Q., Fan, Q. and Gao, X. (2013) Real-time monitoring system for workers' behaviour analysis on a large-dam construction site. International Journal of Distributed Sensor Networks 
Liu, H.; Darabi, H.; Banerjee, P. and Liu, J. (2007). Survey of wireless indoor positioning techniques and systems IEEE Transactions on Systems, Man, and Cybernetics, Part C (Applications and Reviews). 37, 1067-1080. DOI: 10.1109/TSMCC.2007.905750

Nath, T., Attarzadeh, M., Tiong, R. L., Chidambaram, C., \& Yu, Z. (2015). Productivity improvement of precast shop drawings generation through BIM-based process reengineering. Automation in Construction, 54, 54-68.

Navon, R., and Sacks, R. (2007). "Assessing research issues in Automated Project Performance Control (APPC).” Automation in Construction, 16, 474-484.

Olivieri, H., Seppänen, O. and Peltokorpi, A. (2017) Real-time tracking of production control: requirements and solutions. In: Proc. Lean \& Computing in Construction Congress (LC3), Vol. 1 (CIB W78), Heraklion, Greece.

Park, J., Marks, E., Cho, Y. K., and Suryanto W. (2016). Performance test of wireless technologies for personnel and equipment proximity sensing in work zones. Journal of Construction Engineering and Management, 142(1), 04015049. https://doi.org/10.1061/(ASCE)CO.1943-7862.0001031

Pradhananga, N., \& Teizer, J. (2013). Automatic spatio-temporal analysis of construction site equipment operations using GPS data. Automation in Construction, 29, 107-122.

Sacks, R., Radosavljevic, M., and Barak, R. (2010). "Requirements for building information modeling based lean production management systems for construction." Automation in Construction, 19, 641-655.

Sacks, R. (2016). "What constitutes good production flow in construction?" Construction Management \& Economics, 34(9), 641-656.

Sacks, R., Barak, R., Belaciano, B., Gurevich, U., and Pikas, E. (2013). "KanBIM Lean Construction Workflow Management System: Prototype Implementation and Field Testing." Lean Construction Journal, 9, 19-34.

Seppänen, O., Ballard, G., \& Pesonen, S. (2010). The Combination of Last Planner System and Location-Based Management System. Lean Construction Journal.

Seppänen O., Modrich R., Ballard G., 2015. Integration of Last Planner System and Location-Based Management System. In: Proc. 23rd Ann. Conf. of the Int'1. Group for Lean Construction. Perth, Australia, July 29-31, pp. 123-132

Seppänen O., Evinger J., Mouflard C. (2014): Effect of the location-based management system on production rates and productivity, Construction Management and Economics, DOI: $10,1080 / 01446193,2013,853881$ 
Vieira, G. G., Varela, M. L. R., Putnik, G. D., Machado, J., and Trojanowska, J. (2016). Integrated platform for real-time control and production and productivity monitoring and analysis.

Zhao, J., Olivieri, H., Seppänen, O., Peltokorpi, A., Badihi, B., \& Lundström, P. Data analysis on applying real time tracking in production control of construction. In Industrial Engineering and Engineering Management (IEEM), 2017 IEEE International Conference (pp. 573-577). Singapore, 10-13 December, 2017. DOI: 10.1109/IEEM.2017.8289956.

Zhao, J., Seppänen, O., Peltokorpi, A., Badihi, B., \& Olivieri, H. (2019). Real-time resource tracking for analyzing value-adding time in construction. Automation in Construction, 104, 52-65. https://doi.org/10.1016/j.autcon.2019.04.003 